\title{
Diagnostic assessment of haemorrhagic rash and fever
}

H E Nielsen, E A Andersen, J Andersen, B Böttiger, K M Christiansen, P Daugbjerg, S O Larsen, I Lind, M Nir, K Olofsson

\begin{abstract}
Aims-To establish criteria for early distinction between meningococcal disease and other conditions with similar clinical features, and to identify other causes for haemorrhagic rashes accompanied by fever.

Methods-In a prospective study, 264 infants and children hospitalised with fever and skin haemorrhages were studied.

Results-We identified an aetiological agent in 28\%: $15 \%$ had meningococcal disease, $2 \%$ another invasive bacterial infection, $7 \%$ enterovirus infection, and $4 \%$ adenovirus infection. Five clinical variables distinguished between meningococcal disease and other conditions on admission: (1) skin haemorrhages of characteristic appearance; (2) universal distribution of skin haemorrhages; (3) maximum diameter of one or more skin haemorrhages greater than $2 \mathrm{~mm}$; (4) poor general condition (using a standardised observation scheme); and (5) nuchal rigidity. If any two or more of these clinical variables were present, the probability of identifying a patient with meningococcal disease was $97 \%$ and the false positive rate was only $12 \%$. This diagnostic algorithm did not identify children in whom septicaemia was caused by other bacterial species.

(Arch Dis Child 2001;85:160-165)
\end{abstract}

Keywords: meningococcal disease; petechiae; enterovirus; adenovirus

Paediatric

Department, Nykøbing

Falster Hospital

E A Andersen

Department of Virology, Statens

Seruminstitut,

Denmark

B Böttiger

Neisseria Department, Statens Seruminstitut,

Denmark

J Andersen

I Lind

Biostatistical

Departments, Statens

Seruminstitut,

Denmark

S O Larsen

Correspondence to:

Dr Nielsen

Hanie@

gentoftehosp.kbhamt.dk

Accepted 8 January 2001 The simultaneous presence of fever and skin haemorrhages in a child always raises the suspicion of meningococcal disease (MD). While patients with nuchal rigidity or with fulminant purpura and circulatory collapse leave little doubt about appropriate therapeutic procedures, those with only small skin haemorrhages and relatively good general condition represent the real diagnostic challenge and there is a distinct need for a simple algorithm to identify those with meningococcal disease.

In the three published studies of children with fever and petechiae, ${ }^{1-3}$ the frequency of MD varied widely-from $0.5 \%$ to $10 \%$. Among children admitted to hospital with an acute febrile illness and petechiae, $11-19 \%$ had an invasive bacterial infection, most often MD. In the majority, the aetiology remained unknown, but was assumed to be viral. ${ }^{12}$

This prospective and non-interventional study had two main purposes: (1) to develop an algorithm for prediction of $\mathrm{MD}$ in children
Table 1 Diagnostic classification of the 264 patients

\begin{tabular}{llcl}
\hline $\begin{array}{l}\text { Group } \\
\text { no. }\end{array}$ & Definition & Number & $\begin{array}{l}\text { Median } \\
\text { age (mth) }\end{array}$ \\
\hline 1 & $\begin{array}{l}\text { Meningococcal disease, } \\
\text { confirmed }\end{array}$ & 29 & 30 \\
2 & $\begin{array}{l}\text { Meningococcal disease, } \\
\text { probable }\end{array}$ & 10 & 26 \\
& $\begin{array}{l}\text { Invasive bacterial infection, } \\
\text { excluding MD }\end{array}$ & 6 & 14 \\
4 & Enterovirus infection & 18 & 21 \\
5 & Adenovirus infection & 11 & 22 \\
6 & No invasive bacterial disease & 140 & 27 \\
7 & Insufficient information $\dagger$ & 50 & 18
\end{tabular}

For statistical analyses, groups 1 and 2 were pooled and compared to groups 4-6, pooled. The latter group of 169 children were considered to be without invasive bacterial infection. *Either no bacteria in cultures from blood or spinal fluid and no antibiotic treatment prior to culture; or no blood culture, but spontaneous recovery-that is, no antibiotic treatment before or during hospitalisation.

†Either antibiotic treatment prior to blood culture; or no blood culture, but treated with antibiotics.

with fever and skin haemorrhages; and (2) to elucidate the aetiology of disease in those without MD.

\section{Patients and methods}

PATIENTS

Each of the five participating paediatric departments enrolled consecutive patients for exactly 24 months, between September 1993 and June 1996. The paediatric population at risk was 203000 .

Inclusion criteria were: (1) presence of haemorrhages in the skin, irrespective of size, detected at admission or during the stay in hospital; (2) rectal temperature above $38^{\circ} \mathrm{C}$ at some time within the 24 hours before inclusion; and (3) age greater than 1 month and less than 16 years.

There was only one exclusion criterion: if a

child was admitted twice during the study period and fulfilled the inclusion criteria on both occasions, only the first admission was included in the study (there were two such children, neither of whom had MD).

The patients were classified into seven groups as described in table 1 . If a patient fulfilled the criteria for inclusion in more than one group, the classification was hierarchic - that is, the patient was included in the lowest numbered applicable group. All patients included in this study were considered to have illness clinically compatible with MD.

\section{Meningococcal disease}

Cases of MD were defined according to the recommendations used by the British health authorities, ${ }^{4}$ but with the following modifications: the diagnosis of probable cases demanded demonstration of meningococcal antigen or antimeningococcal antibodies as 
described below; and the category of "possible cases" was not used.

- Confirmed case: clinical diagnosis of meningitis or septicaemia confirmed by culture of Neisseria meningitidis from blood and/or spinal fluid

- Probable case: clinical diagnosis of meningitis or septicaemia without culture confirmation, but defined by a significant increase in meningococcal antibody titres (see below), or a high antibody titre in a single serum sample drawn during the second or third week after onset of disease, and/or demonstration of serogroup $\mathrm{A}$ or $\mathrm{C}$ meningococcal capsular polysaccharide in the acute serum sample by counterimmunoelectrophoresis.

The completeness of patient inclusion could only be estimated for those with $\mathrm{MD}$, because data from three different systems of registration were available: (1) the clinical departments' diagnostic files; (2) the national compulsory notification of bacteriologically verified and clinically suspected cases of MD; and (3) a national laboratory surveillance system including all meningococci isolated from patients with MD.

Enterovirus (EV) and adenovirus (AV) infections were defined by demonstration of $\mathrm{EV}$ in serum, of $\mathrm{EV}$ or $\mathrm{AV}$ in throat culture, or seroconversion for $\mathrm{EV}$ antibodies.

\section{METHODS}

Clinical examination at inclusion

Examinations were recorded on preprinted study forms. They included information from the case history and a standardised physical examination which was repeated 6-24 hours later. Table 2 lists the observations. In the physical examination, special emphasis was placed on a description of the skin haemorrhages. The clinician decided whether their appearance matched none, one, or several of the seven types

Table 2 Univariate analysis of explanatory variables, obtained at inclusion, in 39 patients with meningococcal disease and 169 patients without invasive bacterial disease

\begin{tabular}{|c|c|c|c|}
\hline Explanatory variables & $\begin{array}{l}\text { Meningococcal } \\
\text { disease } \\
(n=39)\end{array}$ & $\begin{array}{l}\text { No invasive } \\
\text { bacterial } \\
\text { disease } \\
(n=169)\end{array}$ & $\begin{array}{l}\text { Significance of } \\
\text { difference } \\
\text { ( } p \text { value) }\end{array}$ \\
\hline \multicolumn{4}{|l|}{ Case history prior to inclusion } \\
\hline Fever, median duration (h) & 21 & 24 & n.s. \\
\hline Skin haemorrhages, median duration (h) & 9 & 12 & n.s \\
\hline Antibiotic treatment & $23 \%$ & $2 \%$ & $<0.001$ \\
\hline Coughing & $15 \%$ & $37 \%$ & $<0.05$ \\
\hline Vomiting & $44 \%$ & $40 \%$ & n.s \\
\hline \multicolumn{4}{|l|}{ Physical signs at inclusion } \\
\hline Median temperature $\left({ }^{\circ} \mathrm{C}\right)$ & 40.0 & 39.0 & $<0.01$ \\
\hline Nuchal rigidity & $41 \%$ & $3 \%$ & $<0.001$ \\
\hline General condition, median sum of scores & 6 & 9 & $<0.001$ \\
\hline \multicolumn{4}{|l|}{ Skin haemorrhages } \\
\hline Individuals with $>20$ skin haemorrhages & $74 \%$ & $51 \%$ & $<0.05$ \\
\hline Maximum diameter $>1 \mathrm{~mm}^{\star}$ & $95 \%$ & $22 \%$ & $<0.001$ \\
\hline Maximum diameter $>2 \mathrm{~mm}^{\star}$ & $74 \%$ & $8 \%$ & $<0.001$ \\
\hline Universal distribution & $92 \%$ & $40 \%$ & $<0.001$ \\
\hline Skin haemorrhages of types $C-E$ (fig 1$)$ & $82 \%$ & $7 \%$ & $<0.001$ \\
\hline \multicolumn{4}{|l|}{ Blood tests at inclusion } \\
\hline Leucocytes, $10^{9} / l$, median & 16.5 & 11.6 & $<0.01$ \\
\hline Neutrophil band forms, $10^{9} / l$, median & 1.8 & 0.3 & $<0.001$ \\
\hline Neutrophils, segmented, $10^{9} / l$, median & 10.8 & 5.6 & $<0.01$ \\
\hline Platelets, $10^{9} / l$, median & 226 & 288 & $<0.05$ \\
\hline$C R P, m g / l$, median & 109 & 20 & $<0.001$ \\
\hline APTT, $\%$ prolonged & $23 \%$ & $11 \%$ & n.s. \\
\hline
\end{tabular}

Variables selected for logistic regression analysis are italicised.

${ }^{\star}$ A single lesion of this size was sufficient for this classification.

APTT, activated partial thromboplastin time; CRP, C reactive protein. which were printed on the study form (see fig 1 ; types 1-7 correspond to A-G in the figure). The maximum diameter of the largest haemorrhage was measured with a ruler printed on the study form. Also, their number and distribution above and below the nipple line was documented. For evaluation of the general condition, a simple system adapted from McCarthy and colleagues, ${ }^{5}$ was used (table 3 ).

\section{Clinicopathological tests at inclusion}

Table 2 shows the routine tests. Decisions regarding supplementary tests and treatment were at the discretion of the physician in charge.

\section{Microbiological tests}

Blood cultures were performed on inclusion. Sera were examined for meningococcal, pneumococcal, and Haemophilus influenzae capsular antigens, ${ }^{6}$ meningococcal ${ }^{7} 8$ and $\mathrm{EV}$ antibodies, and EV RNA by polymerase chain reaction (PCR). Throat swabs from both tonsils were cultured for meningococci, ${ }^{10} \mathrm{EV}$, and $\mathrm{AV}$. Convalescent sera, obtained 8-21 days after inclusion, were tested for antibodies against meningococci and $\mathrm{EV}$.

Antigen detection-All serum samples collected at inclusion were examined for meningococcal serogroups A and C capsular polysaccharide antigen, $H$ influenzae type $\mathrm{b}$ capsular polysaccharide antigen, and 23 types of pneumococcal capsular polysaccharide antigen, using counterimmunoelectrophoresis. ${ }^{6}$

Meningococcal antibodies-All acute and convalescent sera were investigated for meningococcal antibodies by the meningococcal antibody test (MAT) and for antibodies directed against meningococcal capsular polysaccharides, serogroups $\mathrm{B}$ and $\mathrm{C}$ at the Neisseria Department, Statens Seruminstitut. The MAT is an in-house complement fixation test using a pool of heat treated whole meningococcal cells as antigen and fresh guinea pig serum as complement source. In $90 \%$ of patients with confirmed MD, seroconversion or a significant increase in antibody titres can be shown 10-15 days after onset of disease. ${ }^{70}$ Antibodies against serogroups $\mathrm{B}$ and $\mathrm{C}$ capsular polysaccharides were shown by an in-house enzyme linked immunosorbent assay (ELISA) as described elsewhere. ${ }^{7}$ Serogroup specific IgM and/or IgG antibodies can be shown in $79-96 \%$ of patients with confirmed MD.

Virus isolation was performed from throat swabs using three different cell types: primary monkey kidney cells; rhabdomyosarcoma cells; and human line cells. Enterovirus IgG antibodies were detected by an indirect ELISA using a synthetic peptide (PALTAVETGATNPL) as antigen. ${ }^{11}$ For Enterovirus PCR, RNA was extracted from $100 \mu$ serum using a Qiagen RNeasy Total Kit. The primers and the PCR method have been described by Nicholson and colleagues. ${ }^{12}$

\section{STATISTICS}

Medians were used to describe the central tendency of the various distributions. Comparisons between distributions were based on the 

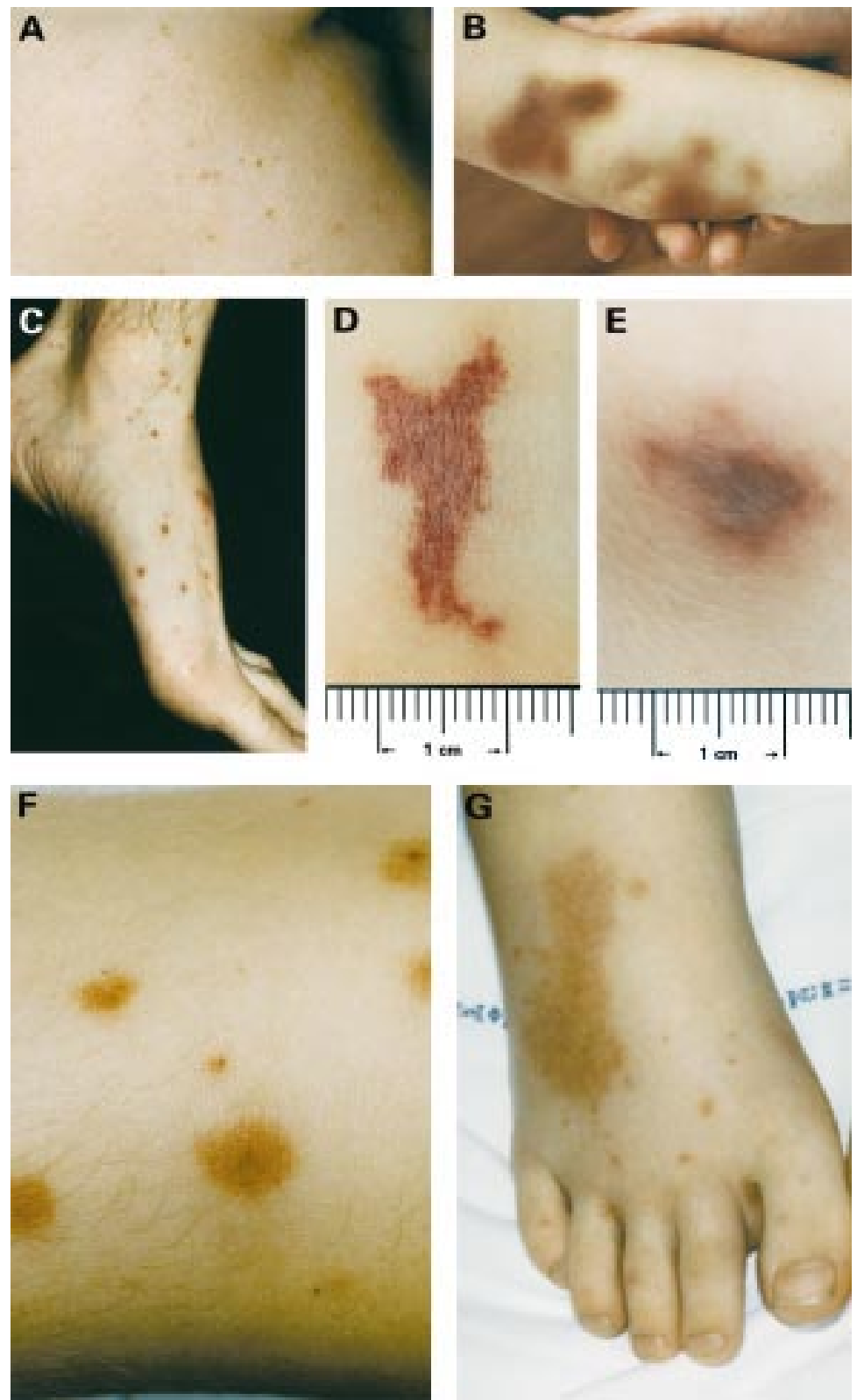

Figure 1 Clinical photos on the study form. The photos are from patients with: micropetechiae $(A)$, type 1 ; thrombocytopenia $(B)$, type 2 ; meningococcal disease $(C-E)$, types 3-5; Henoch-Schönlein purpura $(F, G)$, types 6 and 7.

Wilcoxon two sample test. Proportions were compared by a $\chi^{2}$ test with Yates's correction or by Fisher's exact test. Logistic regression was used to elucidate the diagnostic value of a number of clinical and laboratory parameters, the impact of each variable being expressed as odds ratios in a model with all significant variables entered. For small probabilities the odds ratio is approximately equal to the relative risk, which expresses the risk of being in the MD group relative to the risk of being in the non-MD group when the corresponding clinical sign or laboratory variable is positive.

\section{Results}

A total of 264 patients with fever and skin haemorrhages were included in the study (table 1). Two children died, one as a result of vasculitis of unknown aetiology, and one as a result of pneumococcal meningitis.

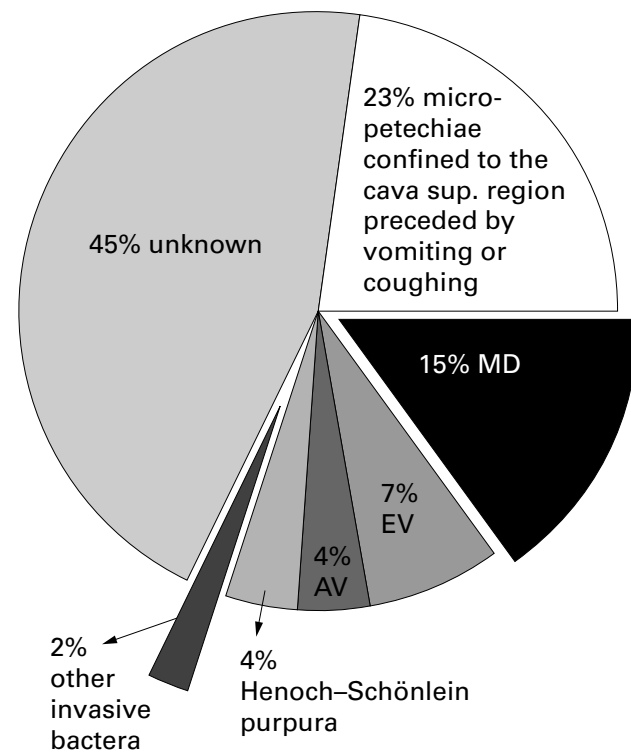

Figure 2 Aetiology or suggested pathophysiological mechanisms in 264 children with fever and skin haemorrhages.

Figure 2 shows the aetiologies and suggested pathophysiological mechanisms of all 264 children. We identified an aetiological agent in only $28 \%$. In a similar proportion we found a pathophysiological explanation: $23 \%$ had micropetechiae only above the nipple line, and had either coughed or vomited. Henoch-Schönlein purpura was present in $4 \%$. In $45 \%$ we found no explanation of the skin haemorrhages.

Among the 264 patients, blood culture was performed in $84 \%$, a complete set of case history information was obtained in $69 \%$, a complete physical examination in $86 \%$, and a complete set of clinicopathological tests in $67 \%$. Lumbar puncture was performed in $32 \%$.

MENINGOCOCCAL DISEASE ( $\mathrm{N}=39$; TABLE 1 , GROUPS 1 AND 2)

The completeness of patient inclusion was estimated for those with MD. Forty one children who fulfilled the inclusion criteria were identified from the registers; 39 of them were included. Two were not included as a result of an error, one of whom died.

Thus 39 patients included in the study had MD: 29 confirmed and 10 probable cases. There were no deaths. In the confirmed cases, the general condition was worse and meningitis was more common than in the probable cases, but there were no other major differences between the two groups. Nine of the 39 patients had been treated with antibiotics prior to admission. All were treated with intravenous antibiotics in hospital, although this was delayed until after the first clinical examination in five. Throat culture was positive for meningococci in 5/30 of those with MD and in 3/145 of those without MD ( $\mathrm{p}<0.01)$.

Among the 10 probable cases of MD, nine showed a significant increase in MAT titre, and one had a high MAT titre in a single serum sample. In four of these 10 patients, a significant increase in antibody titre to capsular polysaccharides was also shown. 
Table 3 Scoring of general condition

\begin{tabular}{|c|c|c|c|}
\hline \multirow[b]{2}{*}{ Points scored } & \multicolumn{3}{|l|}{ Variables } \\
\hline & $\begin{array}{l}\text { Level of consciousness and } \\
\text { reaction to surroundings }\end{array}$ & $\begin{array}{l}\text { Spontaneous motor } \\
\text { activity }\end{array}$ & $\begin{array}{l}\text { Skin colour and } \\
\text { circulation }\end{array}$ \\
\hline 3 & $\begin{array}{l}\text { Normal (awake-or if } \\
\text { asleep—easy to wake up and } \\
\text { stays awake) }\end{array}$ & Normal & Pink \\
\hline 2 & $\begin{array}{l}\text { Moderately reduced (reacts } \\
\text { to surroundings, but does } \\
\text { not stay awake) }\end{array}$ & Slightly reduced & $\begin{array}{l}\text { Hands and feet pale } \\
\text { or cyanotic }\end{array}$ \\
\hline 1 & $\begin{array}{l}\text { Severely reduced (no or only } \\
\text { brief reaction to stimuli) }\end{array}$ & Severely reduced & $\begin{array}{l}\text { Pale or cyanotic or } \\
\text { grey or mottled }\end{array}$ \\
\hline
\end{tabular}

The sum of scores, varying from 3 to 9 , is the measure of the patient's general condition.

Meningococcal serogroup C antigen was found in the serum of three of nine confirmed serogroup C cases.

SEPTICAEMIA OR MENINGITIS WITH OTHER BACTERIAL SPECIES ( $=6$; TABLE 1 , GROUP 3 ) One patient had pneumococcal meningitis and died. Five had septicaemia, caused by pneumococci in two, group A streptococci in one, group B streptococci in one, and Salmonella enteritidis in one. Capsular polysaccharide from $H$ influenzae type b or Streptococcus pneumoniae was not found in any of the acute phase sera. With the exception of the patient with meningitis, the general condition of these six patients at admission was good: in five the sum of scores (table 3) exceeded 6, and the skin haemorrhages were few, small, and of type A (fig 1). Nevertheless, four started intravenous antibiotic treatment at the first clinical examination.

ENTEROVIRUS AND ADENOVIRUS INFECTIONS

$(\mathrm{N}=29$; TABLE 1 , GROUPS 4 AND 5)

$\mathrm{EV}$ and $\mathrm{AV}$ were isolated from the throats of 15 and 11 patients, respectively, of 211 patients tested. Another three patients, of 93 tested, seroconverted for EV IgG antibodies. These 29 patients were considered to have had an acute viral infection as the cause of their disease, corresponding to a prevalence of $11 \%$. Clinically, the children's general condition was good, and in the majority the skin haemorrhages were universally distributed micropetechiae. Enterovirus RNA was not detected in any of 129 serum samples tested.

INSUFFICIENT INFORMATION ( $=50$; TABLE 1 , GROUP 7)

In 50 children invasive bacterial infection could not be excluded owing to antibiotic treatment prior to admission or lack of blood culture. In

Table 4 Logistic regression analysis with selected explanatory clinical and laboratory variables from table 2

\begin{tabular}{lccc}
\hline Explanatory variable & p value & $\begin{array}{l}\text { Adjusted odds } \\
\text { ratio }\end{array}$ & 95\% CI \\
\hline Skin haemorrhages, type C, D, or E (fig 1) & 0.002 & 11.2 & 2.5 to 50.7 \\
Universal distribution of skin haemorrhages & 0.036 & 5.1 & 1.1 to 23.7 \\
Maximum diameter of skin haemorrhages $>2 \mathrm{~mm}$ & 0.012 & 7.0 & 1.5 to 32.0 \\
General condition, score $<7$ & 0.001 & 14.0 & 3.1 to 62.6 \\
Nuchal rigidity & 0.040 & 6.9 & 1.1 to 44.0 \\
Neutrophil band forms $>0.5 \times 10^{9} / 1$ & 0.002 & 38.3 & 3.8 to 385.1 \\
CRP $>68 \mathrm{mg} / 1^{\star}$ & 0.0001 & 12.4 & 4.7 to 32.7
\end{tabular}

The response variable is presence or absence of meningococcal disease.

The two regression analyses - of the clinical and the laboratory variables-were separate.

$\star 68 \mathrm{mg} / \mathrm{l}$ equals $500 \mathrm{nmol} / \mathrm{l}$. The logistic regression analysis was repeated with $136 \mathrm{mg} / \mathrm{l}$ as cut off point; the results were similar.
41 of them a test for bacterial antigens in the initial blood sample and/or a test for antimeningococcal antibodies in convalescent serum were performed, in all cases with negative results.

DIAGNOSTIC ALGORITHM FOR MD

The comparisons shown in tables 2 and 4 are between the 39 individuals with MD and the 169 without invasive bacterial infection (groups 4-6, table 1). The six with other invasive bacterial infections and the 50 with insufficient information were excluded from these analyses.

In order to rate the diagnostic importance of the clinical signs seen at admission, we performed a logistic regression analysis using clinical variables selected from table 2 as explanatory variables, and presence or absence of $\mathrm{MD}$ as the response variable to be predicted. Each of the five clinical variables listed in table 4 independently predicted the presence or absence of MD as shown by the odds ratios given in the table.

As the five clinical variables had odds ratios of the same approximate magnitude, we designed an index (varying from 0 to 5 ) which simply counts the number of the five explanatory variables which were positive. The sensitivity and false positive rates of a diagnostic algorithm based on the index, when different numbers of positive variables were used were: $\geqslant 1,97 \%, 49 \% ; \geqslant 2,97 \%, 12 \% ; \geqslant 3,82 \%$, $5 \%$. These figures should be compared to what was actually done; $87 \%$ (34/39) and $23 \%$ in the two groups did receive intravenous antibiotics at the first clinical examination, before any laboratory results were available.

A standard physical examination was repeated between six and 24 hours after inclusion in each case. The only patient with MD who did not meet the clinical criterion for treatment at inclusion (two or more positive signs), did so at the second physical examination seven hours later. At the first examination, he had only three micropetechiae in the face, and his general condition was good.

Among the laboratory test results performed within a few hours (table 2), leucocyte count, neutrophil counts, platelet count, and C reactive protein (CRP) were selected for regression analysis. Among these, only the absolute band count and the CRP concentration significantly predicted MD (table 4).

The algorithm was not useful for the diagnosis of invasive bacterial infections other than $\operatorname{MD}(\mathrm{n}=6$, group 3, table 1 ) as only $2 / 6$ had an index $\geqslant 2$.

\section{Discussion}

In this prospective study of 264 infants and children hospitalised with fever and skin haemorrhages, we present an analysis of the microbiological aetiology and a proposal for a diagnostic algorithm for the clinical diagnosis of MD; simple clinical observations had a high discriminatory power. We believe that our use of serology, especially the meningococcal antibody $\operatorname{test}^{78}$ made the identification of culture negative cases of $\mathrm{MD}$ more reliable than in 
earlier studies. ${ }^{1-3}$ The experience with the antigen and antibody assays used have been described elsewhere. ${ }^{6-8}$ PCR assays for meningococcal $\mathrm{DNA}^{13}$ were not available at the time of our study, but once they become routinely and rapidly available, may prove useful for validation of our algorithm.

We used our own severity score system, adapted from McCarthy and colleagues, ${ }^{5}$ rather than an established one such as the Glasgow or PRISM score, because only a minority of our patients were expected to have $\mathrm{MD}$ and we needed a generally applicable score that was easy to use.

Earlier studies of children with fever and petechiae ${ }^{1-3}$ are not directly comparable to our study, either because of exclusion of those with shock $^{2}$ or large skin haemorrhages, ${ }^{12}$ or, in one study, because outpatients were included. ${ }^{3}$ In those studies the frequency of $\mathrm{MD}$ varied widely, from $0.5 \%$ to $10 \%$, as did the frequency of septicaemia with other bacterial species $(1-4 \%) .^{1-3}$

In our series the other invasive bacterial species encountered were predominantly streptococci, including pneumococcus. Skin haemorrhages occur with a much lower frequency in septicaemia with organisms other than meningococci, and the mechanism of their development may be quite different - they certainly look different from those caused by MD. This may be the main reason why our diagnostic algorithm, mainly based on the appearance of skin haemorrhages, was inefficient for the diagnosis of septicaemia other than MD.

It is likely that the great majority of our patients had an infectious disease, but we only identified the aetiological agent in $28 \%$ (fig 2). $\mathrm{EV}$ or AV were causes of disease almost as often $(11 \%)$ as meningococci (15\%), while other invasive bacteria accounted for only $2 \%$. These prevalences are minimum estimates as the common denominator will be less than 264 in the different groups of patients as a result of incomplete microbiological studies and antibiotic treatment prior to inclusion.

It is well known that $\mathrm{EV}$ and $\mathrm{AV}$ may give rise to fever and skin haemorrhages in children. ${ }^{14-17}$ In this study, we have considered the isolation of virus from throat swabs and/or a seroconversion for EV antibodies as causally related to the illness, but there is some uncertainty, especially in the case of AV..$^{17}$ The symptoms were nonspecific and it was not possible to make a clinical diagnosis of $\mathrm{AV}$ and $\mathrm{EV}$ infection.

We found a large group of infants with micropetechiae in the superior vena cava distribution consequent on vomiting or coughing - a characteristic clinical picture familiar to all paediatricians. However, vomiting is also common prior to admission in $\mathrm{MD}$ (table 2).

Our data provide an opportunity to describe and formalise a simple diagnostic algorithm. Five clinical variables from table 2 were selected for further analysis; all independently predicted the presence or absence of MD (table 4). If two or more of them were positive, the probability of MD was very high, and relatively few cases without MD would be treated.
Three of the predicting variables were characteristics of the skin haemorrhages (appearance, size, and distribution), showing the importance of this clinical feature. However, assessment of their appearance is difficult for the inexperienced clinician. Perhaps the clinical photographs we used (fig 1) could be improved: there were two pictures of large purpuric lesions, but no picture of the early "flea bitten" maculopapular rash. ${ }^{18}$ As the formulation of our diagnostic algorithm has been generated from our clinical data, it would be preferable if its performance were tested in an independent study. There is one very important proviso to its use: it does not predict septicaemia or meningitis caused by other bacteria-thus these conditions must still be considered in children with scores of 0 or 1 in the diagmostic algorithm.

Laboratory tests may also assist in the decision on treatment. The absolute band count and the CRP were useful (table 4). Other laboratory tests (table 2) may be useful for evaluation of the severity of MD, but are of little assistance when the diagnosis is in doubt in children with fever and skin haemorrhages. Previous studies of children with fever and petechiae ${ }^{1-3}$ also evaluated the laboratory tests and emphasised the importance of the band count $^{119}$ and the CRP concentration on admission..$^{19} 20$

In the present study culture of throat swabs for meningococci was of little predictive value, as it was only positive in $17 \%$ of those with $\mathrm{MD}$; however, this investigation can occasionally be useful in assisting later management decisions.

In conclusion, we have characterised a population of infants and children hospitalised with fever and skin haemorrhages. We suggest a simple diagnostic algorithm for identification of those with MD. Those who are not given antibiotics may be observed in hospital, and treated if they subsequently fulfil the clinical criteria. However, the algorithm did not identify children who had septicaemia or meningitis caused by other bacterial species. Supported by grants from King Christian IX and Queen
Louise's Foundation, Queen Louise's Foundation, and the Louise's Foundation, Queen Louise's Foundation, and the Copenhagen, the Faeroe Islands, and Greenland. The Statistical Consulting Service of the Danish Medical Research Council advised on the design of this study. The assistance of Ms Inge advised on the design of this study. The assistance of Ms Inge
Holm with computations and of the Dept of Clinical PhotograHolm with computations and of the Dept of Clinical Photogra-
phy and Illustration at Gentofte Hospital is gratefully acknowledged.

1 Baker RC, Seguin JH, Leslie N, et al. Fever and petechiae in children. Pediatrics 1989;84:1051-5.

2 van Nguyen Q, Nguyen EA, Weiner LB. Incidence of invasive bacterial disease in children with fever and petechiae. Pediatrics 1984;74:77-80.

3 Mandl V, Stack AM, Fleisher GR. Incidence of bacteraemia in infants and children with fever and petechiae. $\mathcal{F}$ Pediatr 1997;131:398-404.

4 Stuart JM, Monk PR, Lewis DA, et al. Management of clusters of meningococcal disease. Commun Dis Rep 1997;7: R3-5.

5 McCarthy PL, Sharpe MR, Spiesel SZ, et al. Observation scales to identify serious illness in febrile children. Pediatrics 1982;70:802-9.

6 Colding H, Lind I. Counterimmunoelectrophoresis in the diagnosis of bacterial meningitis. F Clin Microbiol 1977;5: 405-9.

7 Andersen J, Berthelsen L, Lind I. Measurement of antibodies against meningococcal capsular polysaccharides $\mathrm{B}$ and

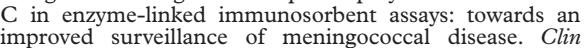
Diagn Lab Immunol 1997;4:345-51.
Dimed surveillance of meningt 
8 Weiss N, Berthelsen L, Lind I. The meningococcal antibody test: how useful to diagnose meningococcal disease? In: test: how useful to diagnose meningococcal disease? In Nassif X et al, eds. The Eleventh International Pathogen Neisseria Conference, Nice, France. Paris. EDK, 1998:141.

9 Weis N, Lind I. Pharyngeal carriage of Neisseria meningitidis before and after treatment of meningococcal disease. $\mathcal{F}$ Med Microbiol 1994;41:339-42.

10 Andersen J, Berthelsen L, Bech Jensen B, Lind I. Dynamics of the meningococcal carrier state and characteristics of the carrier strains: a longitudinal study within 3 cohorts of military recruits. Epidemiol Infect 1998;121:85-94.

11 Samuelson A, Glimåker M, Skoog E, et al. Diagnosis of enteroviral meningitis with IgG-EIA using heat-treated virions and synthetic peptides as antigens. $7 \mathrm{Med}$ Virol 1993;40:271-7.

12 Nicholson F, Meetoo G, Aiyar S, et al. Detection of enterovirus RNA in clinical samples by nested polymerase chain reaction for rapid diagnosis of enterovirus infection. $f$ Virol Methods 1994;48:155-6.

13 Newcombe J, Cartwright K, Palmer WH, McFadden J. PCR of peripheral blood for diagnosis of meningococcal disease. f Clin Microbiol 1996;34:1637-40.
14 Morag A, Ogra PL. Enteroviruses. In: Behrman RE, Kliegman RM, Arvin AM, eds. Nelson textbook of pediatrics. man RM, Arvin AM, eds. Nelson text

15 McIntosh K. Adenoviruses. In: Behrman RE, Kliegman RM, Arvin AM, eds. Nelson textbook of pediatrics. Philadelphia: Saunders, 1996:906-8.

16 Cherry JD. Enteroviruses. In: Feigin RD, Cherry JD, eds. Textbook of pediatric infectious diseases. Philadelphia: Saunders, 1998:1787-839.

17 Cherry JD. Adenoviruses. In: Feigin RD, Cherry JD, eds. Textbook of pediatric infectious diseases. Philadelphia: Saunders, 1998:1666-84

18 Riordan FAI, Thompson APJ, Sills JA, Hart CA. Who spots the spots? Diagnosis and treatment of early meningococcal disease in children. BMF 1996;313:1255-6.

19 Marzouk O, Bestwick K, Thomson APJ, et al. Variation in serum C-reactive protein across the clinical spectrum
of meningococcal disease. Acta Paediatr 1993;82:72933.

20 Borschsenius F, Bruun JN, Michaelsen TE, Tønjun T. Serum C-reactive protein in systemic infections due to Neisseria meningitidis. NIPH Ann 1986;9:15-21.

\section{Headache classification}

According to the 1988 classification of the International Headache Society (IHS) there are 13 different types of headache, the main ones being migraine with aura, migraine without aura, and tension headache. The suitability of this classification for paediatrics and the nosological integrity of the various types have been much debated. Workers in Milan (Livia N Rossi and colleagues. Developmental Medicine and Child Neurology 2001;43:45-51) have tried to distinguish between migraine without aura and tension headache in children, without much success.

To reach a diagnosis of migraine using the IHS criteria there must be: at least five attacks, attacks lasting for two hours or more, nausea or vomiting and/or photophobia plus phonophobia, and at least two of four other criteria (unilateral headache, pulsating character, moderate or severe intensity, aggravation by walking upstairs). They compared this system with one introduced for use in children by Seshia et al in 1995. (The changes from the IHS system were: duration of attacks one hour or more, nausea, vomiting, photophobia, or sonophobia should be severe, and moderate to severe abdominal pain might replace nausea or vomiting, and the four other criteria might include bilateral headache, first degree family history of migraine, and aggravation by other forms of exercise.) Three hundred and twenty children aged 3-14 years (mean 10 years) with recurrent or chronic headache (or both) had their headaches classified by both systems. With either system 291 children $(91 \%)$ had either migraine without aura or tension headache or both. Thirteen had migraine with aura and 16 were unclassifiable. The Seshia system classified more as migraine without aura (186 v 129) and fewer as tension headache $(52 v 75)$ or both (53 $v$ 87). Duration of attacks and aggravation by exertion were not found to be helpful criteria and it is suggested that they should be dropped. Pulsating quality was not a helpful criterion in younger children.

Rossi and colleagues question whether it is appropriate to distinguish between migraine without aura and tension headache in children. They support the theory that migraine with aura, migraine without aura, and tension headache are one end, the middle, and the other end of a spectrum of disorders and that individual children may have symptoms suggestive of each of the three at various times. On the whole, children with less severe headaches tend to be classified in the tension headache group.

Where all this gets us as regards treatment options seems unclear.

ARCHIVIST 